\title{
Türkiye'de Eğitim Sisteminde Okullaşmanın Ekonomik Büyüme Üzerine Etkisi
}

\section{The Impact of Schooling on Economic Growth in Turkish Education System}

\section{Eda DINERİ ${ }^{1}$, Filiz GÖLPEK ${ }^{2}$}

Amaç: $\mathrm{Bu}$ çalışmanın amacı, ilköğretim, orta öğretim ve yükseköğretim düzeyinde kayıt oranlarının ve fiziki sabit sermayenin ekonomik büyüme üzerindeki etkisini 1980-2016 dönemi için incelemektir.

Tasarım/Yöntem: Bu çalışmada, önce geleneksel birim kök testleri ve yapısal kırılmaya izin veren birim kök testi yapılmıs, sonra değişkenler arasında uzun dönemli ilişkinin olup olmadığı Maki es bütünleşme testi ile incelenmiştir.

Bulgular: $\mathrm{Bu}$ incelemede, birden fazla yapısal kırılmaya izin veren Maki eş bütünleşme testinde değişkenler arasında uzun döneml ilişskinin olduğu; FMOLS es bütünleşme katsayı tahminci sonuçlarında yükseköğretim kayıt oranlarının ve sabit fiziki sermayenin ekonomik büyüme üzerinde etkisinin istatiksel olarak anlamlı ve pozitif yönde olduğu tespit edilmistir. Toda - Yamamoto nedensellik testi sonucunda da, orta öğretim ve yükseköğretim kayı oranlarından ekonomik büyümeye ve fiziki sermayeye tek yönlü nedensellik ilișkisinin olduğu ortaya konulmuștur.

Sınırlılıklar: Çalışmada beşeri sermaye unsurlarından sadece eğitim boyutu incelenmesi araștırmanının sınırlılıklarıdır.

Özgünlük/Değer: Eğitim düzeylerine göre okullaşma oranlarının ekonomik büyüme üzerindeki etkisinin incelenmesi açısından literatüre katkı sağlayabilecek sonuçlara ulaşması araştırmanın özgün değerini olușturmaktadır.

Anahtar Kelimeler: Beşeri Sermaye, Eğitim, Ekonomik Büyüme, Zaman Serisi

\section{Abstract}

Purpose: The aim of this study is to examine the effects of enrollment rates at primary, secondary and higher education levels and physical fixed capital on economic growth for the period 19802016.

Design/Methodology: In this study, firstly, traditional unit root tests and unit root tests that allow structural break were done, and then whether there is a long-term relationship between variables was examined with Maki cointegration test.

Findings: In this review, there is a long-term relationship between variables in Maki cointegration test that allows multiple structural breaks; in the results of FMOLS cointegration coefficient estimators, the effect of higher education enrollment rates and fixed physical capital on economic growth was found to be statistically significant and positive. As a result of the Toda - Yamamoto causality test, it was revealed that there is a one-way causality relationship from secondary education and higher education enrollment rates to economic growth and physical capital.

Limitations: It is the limitations of the study that only the education dimension, which is one of the human capital elements, was examined in the study.

Originality/Value: The original value of the study is that it reaches results that can contribute to the literature in terms of examining the effect of schooling rates on economic growth according to education levels.

Keywords: Human Capital, Education, Economic Growth, Time Series

Dr. Öğr. Üyesi, Hasan Kalyoncu Üniversitesi, İktisadi, İdari ve Sosyal Bilimler Fakültesi, İktisat Bölümü, eda.dineri@hku.edu.tr, ORCID: 0000-0002-5637-594X

2 Doç. Dr., Hasan Kalyoncu Üniversitesi, İktisadi, İdari ve Sosyal Bilimler Fakültesi, İktisat Bölümü, filiz.golpek@hku.edu.tr, ORCID: 0000-0001-9213-1478 


\section{GİRIŞ}

Ülkelerin bilgi toplumuna geçmesinde bireysel, sosyal ve ekonomik refahın oluşturulmasını kolaylaştıran, bireylerde bilgi, beceri, yetkinlik ve özellik olarak tanımlanan beşeri sermayenin rolü giderek artmaktadır (Acemoglu \& Angrist, 1999). Özellikle 1980'li yıllarda içsel ekonomik büyüme teorilerinde ve uzun dönem büyümede geleneksel üretim faktörlerine beşeri sermaye yanında teknoloji de eklenmiş, ülkelerde ve sektörlerde eğitim, araştırma ve uygulama geliştirilen bir süreç haline gelmiştir (Barro, 1991). Beşeri sermayenin makro ve mikro açıdan gelir artışı yaratması sermaye stokunu artırabilmesi için eğitim yatırımları, okullaşma oranları ve eğitim kalitesi faktörlerine bağlı olduğu konusunda iktisatçılar arasında görüş birliği bulunmaktadır (Hanif \& Arshed, 2016; Wigley \& Akkoyunlu-Wigley, 2008; Blundell vd., 2005). Bu faktörlerden biri olan eğitim yatırımların artırılması, bir yandan uzun vadede yüksek getiri sağlayarak ülkelerin sürdürülebilir ekonomik büyüme ve kalkınmasına ivme kazandırmakta, diğer yandan bireysel gelirleri arttırmaktadır. Bununla birlikte yoksulluğun azaltılması, esnek ve sağlıkı bir çevreyi teşvik etmesi ve rekabet edilebilirliği artırması gibi katkıları eğitim yatırımlarının ne kadar önemli bir unsur olduğunu göstermektedir (Afzal vd., 2010: 39). Örneğin, Oxaal (1997) ile Brown ve Park (2001) çalışmalarında, yoksul ülkelerin genellikle daha düşük okullaşma oranına sahip olduğunu, eğitim yatırımları yeterli olmadığı için çocukların eğitimden daha az faydalandığını ifade etmişlerdir. Wedgwood (2007) çalışmasında, Tanzanya'da ilköğretim ve ortaöğretim seviyesinde eğitim sisteminin geliştirilmesi ile yoksulluğun azaltılabileceğini; Çalışkan (2007) ve Njong (2010) çalışmalarında, eğitim seviyesi yükseldikçe yoksulluk oranının azaldığını vurgulamışlardır.

Yükseköğretim seviyesinde brüt okullaşma oranları incelendiğinde 2016 yılında Avrupa Birliği (AB)'de \%68,3, OECD \%74,40 ve Türkiye'de \%103,74'dür (OECD, 2019). Bu oran, Türkiye'de daha yüksek düzeyde olmasına rağmen, çağının getirdiği bilgiye dayalı mal ve hizmet üretimi geliştirme konusunda geri planda kalmaktadır. Bir ülkenin, ülkeler arasında rekabetin temel belirleyicisi olan bilgiye dayalı, inovatif mal ve hizmet üretiminde yeterli olmaması ülkenin ekonomik büyüme açısından da geri kalmasının bir nedeni olmaktadır. AB ve OECD ülkeleri ile kıyaslandığında kişi başına düşen gelirin Türkiye'de düşük olması da bunu göstermektedir. Okullaşma oranları eğitim sisteminde önemli bir faktör olmakla birlikte okullaşma oranlarının eğitim sisteminde bireyin ve toplumun gelişmesinde rol oynayan diğer faktörlerle birlikte büyümeye katkı sağlayacağı bir gerçektir. Bu kapsamda okullaşma oranları ile birlikte eğitime yapılan harcamalar da eğitim de önemli bir etken olarak karşımıza çıkmaktadır. Örneğin, Keller (2006) çalışmasında, 1960-2000 dönemi için gelişmiş ve gelişmekte olan ülkelerde ilköğretim, orta öğretim ve yükseköğretim seviyelerindeki kayıt oranları, kamusal harcamaları ve öğrenci başına harcamaları analiz etmiştir. Yazar analizde, orta ve yükseköğretim seviyelerindeki okullaşma oranlarını arttıran ülkelerin, ilköğretimde ağırlıklı olmak üzere kişi başına düşen kamu harcamalarını artırdığını tespit etmiştir. Pamuk ve Bektaş (2014) çalışmasında, Türkiye'de 1998- 2013 dönemi için eğitim harcamaları ile ekonomik büyüme arasında uzun dönemli bir ilişki tespit etmezken, ekonomik büyümeden eğitim harcamalarına doğru nedensellik ilişkisi bulmuştur. Yazarlar, ülkenin sürdürülebilir büyüme ve rekabet edilebilir düzeyde olabilmesi için eğitim yatırımlarının önemine vurgu yapmıştır. Gün geçtikçe Türkiye'de niceliksel olarak değişmeler de artış görünse de eğitimin çıktısının birey ve toplumda yarattığı katkının ve değişimin üzerinde durulması gerekmektedir. Çünkü niceliksel değişmeler beşeri sermaye birikiminde önemli olmakla birlikte, ülkenin ekonomik büyüme ve kalkınmasında eğitimin kalitesi belki de daha fazla önemli bir rol oynamaktadır. Örneğin Türkiye'de kamu kaynaklarından eğitim harcamalarına ayrılan pay yıllar itibari ile artış göstermesine rağmen nüfusun da sürekli artı̧̧ göstermesi nedeniyle yetersiz kalmakta (Taban \& Kar, 2014), ayrıca beşeri sermaye indeks sıralamalarında da ilerleme kaydetmemektedir. Bu da göstermektedir ki ülkenin eğitimin iyileştirilmesi konusunda hem niceliksel hem de niteliksel olarak adımlar atmasını göstermektedir. Tablo 1'de Bazı OECD ülkelerinde, 20002016 döneminde eğitim harcamalarına Gayri Safi Yurt İçi Hasıla'dan (GSYİH) ayırdığı pay yer almaktadır. 
Tablo 1: 2000-2016 Döneminde Bazı OECD Ülkelerinde Eğitim Harcamalarının GSYH İçerisindeki Payı (\%)

\begin{tabular}{|c|c|c|c|c|c|c|}
\hline Yillar & Avustralya & Hollanda & Yeni Zelanda & Norveç & İsveç & OECD (ort.) \\
\hline 2000 & 4,89 & 4,58 & 6,56 & 6,46 & 6,74 & 4,78 \\
\hline 2001 & .. & 4,69 & 6,56 & 6,83 & 6,61 & 4,96 \\
\hline 2002 & .. & 4,80 & 6,40 & 7,43 & 6,92 & 5,17 \\
\hline 2003 & .. & 5,04 & 6,43 & 7,41 & 6,79 & 5,09 \\
\hline 2004 & 4,91 & 5,06 & 6,51 & 7,29 & 6,66 & 4,96 \\
\hline 2005 & 4,89 & 5,10 & 6,27 & 6,86 & 6,50 & 5,17 \\
\hline 2006 & 4,75 & 5,04 & 5,95 & 6,38 & 6,36 & 5,09 \\
\hline 2007 & 4,66 & 4,88 & 5,91 & 6,53 & 6,17 & 4,71 \\
\hline 2008 & 4,63 & 5,02 & 5,50 & 6,28 & 6,34 & 4,93 \\
\hline 2009 & 5,08 & 5,43 & 6,28 & 7,10 & 6,74 & 5,43 \\
\hline 2010 & 5,55 & 5,48 & 7,00 & 6,74 & 6,52 & 5,39 \\
\hline 2011 & 5,07 & 5,46 & 6,93 & 6,45 & 6,36 & 5,13 \\
\hline 2012 & 4,86 & 5,41 & 7,15 & 7,37 & 7,53 & 5,14 \\
\hline 2013 & 5,22 & 5,52 & 6,69 & 7,48 & 7,61 & 5,14 \\
\hline 2014 & 5,16 & 5,45 & 6,34 & 7,69 & 7,57 & 5,10 \\
\hline 2015 & 5,31 & 5,34 & 6,33 & 7,56 & 7,44 & 5,01 \\
\hline 2016 & 5,27 & 5,47 & 6,43 & 8,03 & 7,61 & 4,99 \\
\hline
\end{tabular}

Kaynak: The World Bank, 2019

GSYH'den eğitim harcamalarına ayrılan pay, Türkiye'de \%4,3 iken OECD ortalamas1 $\% 4,99$ 'dur. Bu oran İngiltere'de \%5,5, Yeni Zelanda'da \%6,3 İsveç ve Norveç'te \%7,6 ile OECD ortalamasının üzerindedir. OECD ülkelerinin içerisinde yer almayan Moldova (\%6.68), Senegal (\%6.19), Umman (\%6.10), Malta (\% 5.26), Kirgizistan (\%7.20), Kore (\%5.25), Arjantin (\%5.57), Belize (\%7.08), Şili (\%5.35), Çek Cumhuriyeti (\%5.78), Finlandiya (\%7.09), Gana (\%5.76), Jamaika $(\% 5.26)$, Kenya (\%5.24) ülkelerinin de eğitim harcamalarına ayrılan pay OECD ortalamasının (\% $5.23)$ üzerinde yer almaktadır.

Nüfusu giderek artış gösteren Türkiye'de okullaşma oranlarında yukarı yönlü bir ivme göstermesine karşın eğitim harcamaları hem nüfusa göre hem de milli gelir ve beşeri sermaye açısından gelişmiş ülkelere göre düşüktür. Yapılan yatırımlar ile bireylerin üretim becerisi artarken, eğitime sahip olanlar ile olmayanlar arasında verimlilik farkı yaratarak daha yüksek beceriye sahip olunmaktadır (Oxaal, 1997: 3). Literatür çalışmalarında okullaşmanın ve eğitim harcamalarının pozitif ekişi olduğu yönünde sonuçlara ulaşılmaktadır. Örneğin Mincer (1974) çalışmalarında, işçi başına çıktı ile okullaşma oranı arasında bir ilişkinin olduğunu ve okullaşma yılı arttıkça bireysel kazancın arttığını tespit etmiştir. Psacharopoulos ve Patrinos (2004) çalışmalarında, eğitimin özel ve sosyal getirisi olduğunu, ilk ve orta öğretim seviyesinde sosyal, yükseköğretim seviyesinde ise özel getirinin daha yüksek olduğunu tespit etmiştir.

$\mathrm{Bu}$ çalışmada okullaşmanın ekonomik büyüme üzerindeki etkisi eğitim düzeylerine göre ayrılarak incelenmektedir. Çalışmanın ikinci bölümü literatür çalışmalarını içermektedir. Üçüncü bölümde Türkiye'deki eğitim sisteminin gelişiminden bahsedilmektedir. Araştırmanın yöntemi ve analiz sonuçları dördüncü kısımda yer almaktadır. Son bölümde de sonuç ve politika önerilerine yer verilmektedir.

\section{LITERATÜR}

Eğitimin ekonomik büyüme üzerindeki etkisi ile ilgili yapılan ampirik çalı̧̧maların çoğunda farklı eğitim düzeylerinde okullaşmanın etkisi incelenmektedir.

Mincer (1974), "Schooling, experience and earnings" adlı çalışmasında, eğitim ile bireyler tarafından elde edilen kazanımlara ve kalitesine göre ücretlerin farklılaştığını tespit etmiştir. Becker (1975), kolej ve lise eğitiminin parasal olarak getiri oranını hesaplamıştır. Lucas (1988), "On the mechanics of economic development" adlı çalışmasında, beşeri sermayenin büyüme sürecinde rolü ile ilgili ilk katkıyı vurgulamış, diğerlerinden farklı olarak ilköğrenim ve orta öğrenim yerine yükseköğrenim ile ilgili çalışmıştır. Ayrıca yazar çalışmasında, beşeri sermayede okullaşma kadar işte yaparak öğrenme modelinin de önemli olduğunu belirtmiştir. Barro (1991) eğitimin yetişkin erkeklerin 
orta ve daha yüksek düzeylerde öğretimde ekonomik büyümeyi olumlu yönde etkilediğini tespit etmişlerdir.

Chatterji (1998) çalışmasında, üniversite eğitiminin ekonomik büyümede önemli bir rol oynadığını belirtmiş; Bils ve Klenow (2000), okul kayıt oranları artışının verimlilikte ve kişi başına milli gelirde artışına neden olduğunu; Eric (2000), işgücünün kalitesinin okullaşma ile ilgili olduğunu ve ekonomik büyümeye etki ettiğini belirtmişlerdir. Keller (2006), Doğu Asya ülkelerinde 1960-2006 dönemi için eğitimin ekonomik büyüme üzerinde anlamlı ve pozitif etkisinin olduğunu, ancak ilköğretimde okullaşmanın kişi başına büyümede doğrudan etkisi olmadığını, dolaylı olarak doğurganlık oranlarını düşürerek, fiziki sermaye yatırımını ve orta öğrenim kayıtlarının artırarak kişi başına büyüme üzerinde etkisi olduğunu tespit etmiştir. Abbas ve Foreman-Peck (2007), Pakistan için 1970-2009 döneminde iyi eğitimli beşeri sermayenin ekonomik büyüme üzerinde olumlu etki yarattığı ve okullaşmanın ekonomik büyüme üzerinde, hem kısa hem de uzun dönemde pozitif etkisinin olduğunu tespit etmişlerdir. Seetenah (2009), 40 Afrika ülkesinde 1980- 2000 dönemi için eğitimin ekonomik büyüme üzerinde belirleyici bir unsur olduğunu ortaya koymuştur. Reza ve Widodo (2013), Endonezya'da kişi başına eğitimin ekonomik büyüme üzerinde istatiksel olarak anlamlı ve pozitif yönde etkisine vurgu yapmışlardır. Benos ve Zotou (2014) çalışmalarında eğitimin ekonomik büyüme üzerinde pozitif etkisini tespit etmişlerdir.

Ali vd. (2016), eğitimin ekonomik büyüme üzerinde etkisi olduğunu ve bireylerin verimliliğini artırdığını; Teixeria ve Querios (2016), Akdeniz ülkelerinde 1990-2001 dönemi için beşeri sermayenin ekonomik büyüme üzerinde pozitif etkisinin olduğunu ve Miyazawa (2017), II. Dünya Savaşı'ndan sonraki dönemde zorunlu eğitimin genişletilmesinin ekonomik büyümeyi arttırdığını saptamış ve Mincer- type ücret fonksiyonu ile tahmini eğitim yıllarını beşeri sermayeye dönüştürerek, büyüme muhasebesi ile ekonomik büyümeye katkısını hesaplamıș, lise ve üniversite kayıt oranlarındaki artısıın ekonomik büyüme üzerinde pozitif etkisi olduğunu bulmuştur.

Hanif ve Arshed (2016), dinamik panel veri analizini kullandıkları çalışmalarında üniversite eğitiminin ilköğretim ve ortaöğretim kayıtlarına göre ekonomik büyüme üzerinde daha çok etkisi olduğunu tespit etmişlerdir. Kotaskova vd. (2018), Hindistan'da 1975-2016 dönemi için eğitim ile ekonomik büyüme arasında pozitif ilişki tespit ederken, yükseköğretim ile ekonomik büyüme arasında diğer eğitim seviyelerine göre daha yüksek korelasyon ilişkisi bulmuştur.

Eğitim düzeylerine göre okullaşmanın ekonomik büyüme üzerinde pozitif etkisinin olduğu çalışmalar dışında negatif etkisinin bulunduğu çalışmalarda yer almaktadır. Constani ve Monni (2008), 95 ülkeyi inceledikleri çalışmasında 1970-2003 dönemi arasında orta öğretim okullaşma oranlarının, Földwari ve Van Leeuwen (2009), 21 OECD ülkesinde okullaşmanın ekonomik büyüme üzerinde negatif etkisi olduğunu ortaya koymuşlardır.

Türkiye için incelenen çalışmalarda; Canbolat (2000), 1950-1990 döneminde lise ve yüksekokul öğrenci sayısındaki artışa karşın beşeri sermaye stokunda kayda değer bir artış bulamazken, 1965-1990 dönemi için beşeri sermayenin ekonomik büyüme üzerindeki katkısını \%40 olarak tespit etmiştir. Çoban (2004), 1980-1997 döneminde Türkiye'de ilkokul, lise, yüksekokul seviyesinde okullaşma oranlarının ekonomik büyüme üzerinde pozitif yönde etkisi olduğunu; Afşar (2009), Türkiye'de 1963-2005 dönemi için eğitim yatırımlarından ekonomik büyümeye doğru tek yönlü nedensellik ilişkisinin olduğunu belirtmişlerdir. Özsoy (2010), çalışmasında eğitim düzeyleri ile GSYİH arasında uzun dönemli bir ilişkinin olduğunu VAR modeli ile test etmiştir. Telatar ve Terzi (2010), 1968-2016 dönemi için ekonomik büyümeden yükseköğretim mezunu öğrenci sayısına nedensellik ile meslek lisesi mezunu öğrenci sayısından ekonomik büyümeye doğru nedensellik ilişkisinin varlığını ortaya koymuşlardır. Gümüş ve Kayhan (2012), Toda-Yamamoto nedensellik yöntemini kullandıkları çalışmada 1980-2008 döneminde kişi başına milli gelir ile okullaşma oranı arasında ilköğretim seviyesindeki kayıt oranı ile kişi başına milli gelir arasında çift yönlü; kişi başına gelirden orta öğretime doğru tek yönlü nedensellik ilişkisinin olduğunu, yükseköğretim seviyesinde de okullaşma oranı ile kişi başına milli gelir arasında ilişkinin olmadığını tespit etmişlerdir. Akçacı (2013), Toda-Yamamoto nedensellik testi ile 1998Q1-2012Q3 döneminde eğitim harcamalarından ekonomik büyümeye doğru ilişki bulmuştur. Pamuk ve Bektaş (2014), 1998-2013 dönemi için çeyrek verileri kullanarak Türkiye'de eğitim harcamaları ile ekonomik büyüme arasında uzun dönemli bir 
ilişkinin olmadığını ancak, eğitim harcamalarından ekonomik büyümeye doğru tek yönlü nedensellik ilişkisinin olduğu sonucuna ulaşmışlardır. Gövdeli (2016), 1923-2014 dönemi arasında Türkiye'de eğitim ile ekonomik büyüme arasındaki ilişkiyi incelemiş ve uzun dönemde öğrenci sayısı ile ekonomik büyüme arasında ilişki tespit etmişlerdir. Ekonometrik çalışmaların dışında Yeşilyurt vd. (2016), Türkiye'de illere göre ortalama okullaşma yılı ile beklenen okullaşma yılını hesaplamışlardır. Literatür çalışmalarından elde edilen ortak sonuç yükseköğretimde okullaşmanın ekonomik büyüme üzerinde uzun dönemde pozitif etkisi olduğu sonucuna ulaşılmaktadır.

\section{TÜRKIYYE EĞITIMM SISTEMININ GELISSIMI}

Türkiye eğitim sistemini okul öncesi, ilkokul, ortaokul, lise ve üniversite olmak üzere beş basamaktan oluşmaktadır. Okul öncesi ve üniversite öğretimi isteğe bağlı iken ilköğretim ortaokul ve lise zorunlu 12 yıllık eğitimden oluşmaktadır. 30 Mart 2012 tarihinde kabul edilen kanun ile 4 yıl ilkokul, 4 yıl ortaokul ve 4 yıl lise zorunlu öğrenim görülmektedir. Ancak Türkiye'de uzun yıllar boyunca sürdürülebilirlik gösteren bir eğitim politikası uygulanamadığı için sürekli yapılan değişiklik eğitim sisteminin uzun dönemde ekonomik ve sosyal açıdan etkilerini görebilmesini engellemektedir. Bunun en önemli nedeni ise, ülkedeki parlamenter seçimlerin sonucu olarak Milli Eğitim Bakanlığ1 sisteminde de değişiklik olmasıdır. Kısa süreli aralıklarla Bakanlığın değişmesi izlenen eğitim politikalarında istikrarsızlığa neden olmuş ve okul öncesi eğitimden üniversiteye kadar sistemli ve kalıcı bir politika uygulanamamıştır (Gür \& Çelik, 2009: 12).

Avrupa Politikası İşbirliği (ET 2020 Çerçevesi), 2020 yılında çocukların \%95'inin okul öncesi eğitime katılımlarını sağlamayı hedeflemektedir. Avrupa ülkelerinde okul öncesinden başlamak üzere eğitime katılımı gün geçtikçe artmaktadır. 2020 hedef program çerçevesinde 2014 yılında \%95'e yakın düzeyde katılım sağlanmıştır (European Comission, 2016: 10). Türkiye'de bu oran 2017 yılında \%84 düzeylerine yaklaşmıştır. Tablo 2'de okul öncesi okullaşma oranlarına yer verilmektedir.

Tablo 2: 2008-2016 Döneminde Brüt Okul Öncesi Okullaşma Oranları (\%)

\begin{tabular}{lcccccccccc}
\hline & $\mathbf{2 0 0 8}$ & $\mathbf{2 0 0 9}$ & $\mathbf{2 0 1 0}$ & $\mathbf{2 0 1 1}$ & $\mathbf{2 0 1 2}$ & $\mathbf{2 0 1 3}$ & $\mathbf{2 0 1 4}$ & $\mathbf{2 0 1 5}$ & $\mathbf{2 0 1 6}$ & $\mathbf{2 0 1 7}$ \\
\hline Düşük Gelirli Grubu Ülkeler & 14.21 & 14.66 & 14.86 & 15.47 & 17.58 & 18.20 & 18.95 & 19.95 & 21.23 & 21.52 \\
\hline Orta Gelir Grubu Ülkeler & 35.77 & 36.48 & 37.14 & 39.93 & 43.19 & 46.10 & 46.29 & 47.42 & 50.43 & 51.93 \\
\hline Üst- Orta Gelir Grubu Ülkeler & 54.96 & 55.93 & 57.30 & 61.21 & 66.13 & 69.3 & 71.88 & 71.93 & 74.06 & 74.80 \\
\hline OECD & 79.10 & 79.42 & 80.45 & 81.42 & 82.27 & 77.85 & 78.61 & 78.77 & 79.68 & 79.56 \\
\hline Avrupa Birliği & 91.66 & 92.02 & 93.07 & 94.07 & 94.46 & 94.09 & 95.11 & 95.05 & 96.07 & 96.18 \\
\hline Dünya (ortalama) & 37.49 & 38.03 & 38.68 & 40.84 & 43.56 & 45.61 & 45.92 & 46.88 & 49.32 & 50.36 \\
\hline
\end{tabular}

Kaynak: The World Bank, 2019

\section{ARAŞTIRMANIN YÖNTEMI}

Bu çalışmada, Türkiye'de 1980-2016 dönemi için ilköğretim, ortaöğretim ve yükseköğretim seviyelerinde kayıt oranlarının ekonomik büyüme üzerindeki etkisi incelenmektedir. Yıllık verilerin ele alındığı çalışmada ilkokul, ortaöğretim ve yükseköğretimdeki kayıtları, fiziki sabit sermaye yatırımları ve 2010 sabit fiyatları ile dolar cinsinden kişi başına reel gayri safi yurt içi hâsıla verileri için The World Bank veri tabanından yararlanılmıştır. Değişkenlerden ilköğretim (primary), ortaöğretim (secondary) ve yükseköğretim kayıt oranları (tertiary) ve sabit fiziki sermaye yatırımları (physical capital) oransal olarak kullanılırken, kişi başına reel gayrisafi yurt içi hasılanın (gdp) logaritması alınmışıtır. Cobb - Douglas üretim fonksiyonunda yer alan üretim faktörlerinden olan sermaye yerine fiziki sabit sermaye yatırımları, işgücü yerine de okul kayıt oranlarının kullanıldığı modelin formülasyonu aşağıdaki şekilde oluşturulmuştur:

$$
g d p_{t}=\beta_{0}+\beta_{1} \text { tertiary }_{t}+\beta_{2} \text { secondary }_{t}+\beta_{3} \text { primary }_{t}+\beta_{4} \text { physical capital }_{t}+u_{t}
$$

\subsection{Araştırmanın Veri Seti}

Çalışmanın birinci aşamasında, değişkenlerin durağanlığını test etmek için ADF (Augmented Dickey Fuller) ve PP (Phillips Perron) birim kök testlerinden ve bir kırılmaya izin veren Zivot Andrews birim kök testi uygulanmıştır. Geleneksel birim kök testlerinden olan ADF ve PP birim testlerinde yapısal değişimler dikkate alınmazken, kırılmaların içsel olarak belirlendiği Zivot Andrews birim kök testinde yapısal kırılmalar dikkate alınmaktadır. Dickey - Fuller (1981) tarafından geliştirilen ADF birim kök testinin formülasyonu şu şekildedir (Dickey \& Fuller, 1979): 
$\Delta Y_{t}=\beta_{1}+\beta_{2} t+\delta Y_{t-1}+\sum_{i=1}^{k} \alpha_{i} \Delta Y_{t-i}+u_{t}$

$\Delta Y_{t-i}$, gecikmeli fark terimlerini ifade etmektedir. Gecikmeli fark terimleri, hata terimlerinin ardışık bağımsız olmasını sağlarken, $k$ terimi, gecikme uzunluğunu ifade etmektedir. ADF birim kök testinde yer alan boş hipotez birim kökün varlığını, alternatif hipotez ise birim kökün olmadığını yani, durağan olduğunu ifade etmektedir. ADF ve PP (1988) birim kök testleri, benzer hipotezleri içermekle birlikte ADF birim kök testinden farklı olarak oto korelasyon sorununu çözmektedir. Buna göre, PP testi için oluşturulan model aşağıdaki biçimde ifade edilmektedir:

$Y_{t}=\mu_{1}+\emptyset_{1}+Y_{t-1}+u_{t}$ (Sabit terimli)

$Y_{t}=\mu_{1}+\beta\left(t-\frac{1}{2} \lambda\right)+\emptyset_{1} Y_{t-1}+u_{t}$ (Sabit terimli ve eğimli katsayı)

Birim kök testleri sonucunda elde edilen test istatistiği, kritik değerlerden büyük ise boş hipotez reddedilmektedir. Değişkenlerdeki yapısal kırılmaları dikkate almadığı için ADF ve PP birim kök testleri, taraflı ve sahte sonuçlar verdiği yönünde eleştirilmektedir.

Bu nedenle çalışmada, bir kırılmalı yapısal değişime izin veren Zivot - Andrews birim kök testi (1992) uygulanmıştır. Zivot - Andrews birim kök testi, boş ve alternatif hipotezi üç parametre içermektedir. Bunlar aşağıda gösterilmektedir (Zivot \& Andrews, 1992: 252):

$$
\begin{aligned}
& y_{t}=\mu+\beta_{t}+\alpha y_{t-1}+\theta_{1} D U(\varphi)+\sum_{i=1}^{k} c_{i} \Delta_{t-i}+u_{t} \\
& y_{t}=\mu+\beta_{t}+\alpha y_{t-1}+\theta_{2} D T(\varphi)+\sum_{i=1}^{k} c_{i} \Delta_{t-i}+u_{t} \\
& y_{t}=\mu+\beta_{t}+\alpha y_{t-1}+\theta_{2} D T(\varphi)+\theta_{2} D U(\varphi)+\sum_{i=1}^{k} c_{i} \Delta_{t-i}+u_{t}
\end{aligned}
$$$$
\text { (Model A) }
$$$$
\text { (Model B) }
$$

Model A, düzeyde kırılmayı; Model B, trend eğiliminde kırılmayı ve Model C, serilerin hem düzeyde hem de trenddeki kırılmalarını içermektedir. $t=1,2, \ldots$ T zamanı; $D U$ ve $D T$ ise, ortalama her kırılma meydana gelen ortalama kukla değişkenini ifade etmektedir.

Çalışmanın ikinci aşamasında, Maki (2012) tarafından geliștirilen birden fazla yapısal kırılmaya izin verilen ve 4 modeli bulunan eş bütünleşme testinden yararlanılmıştır. Bu modeller aşağıda gösterilmiştir:

Model 0: Sabit terimde kırılmaya izin veren trendsiz model:

$$
Y_{t}=\mu+\sum_{\mathrm{I}=1}^{k} \mu_{i} K_{i, t}+\beta x_{t}+\sum_{\mathrm{I}=1}^{k} \beta_{i} X_{i} K_{i, t}+u_{t}
$$

Model 1: Sabit terimde ve eğimde kırılmaya izin veren trendsiz model

$$
Y_{t}=\mu+\sum_{\mathrm{I}=1}^{k} \mu_{i} K_{i, t}+\beta x_{t}+u_{t}
$$

Model 2: Sabit terimde ve eğimde kırılmaya izin veren trendli model:

$$
Y_{t}=\mu+\sum_{\mathrm{i}=1}^{k} \mu_{i} K_{i, t}+y x+\beta x_{t}+\sum_{\mathrm{i}=1}^{k} \beta_{i} X_{i} K_{i, t}+u_{t}
$$

Model 3: Sabit terimde, eğimde ve trendde kırılmaya izin veren model:

$$
Y_{t}=\mu+\sum_{\mathrm{I}=1}^{k} \mu_{i} K_{i, t}+y x+\sum_{\mathrm{I}=1}^{k} y_{i} t K_{i, t}+\beta x_{t}+\sum_{\mathrm{i}=1}^{k} \beta_{i} X_{i} K_{i, t}+u_{t}
$$

Buna göre, Maki eş bütünleşme testi altında kurulan hipotezler şunlardır:

$\mathbf{H}_{\mathbf{0}}$ : Yapısal kırılmalar altında değişkenler arasında eş bütünleşme ilişkisi yoktur.

$\mathbf{H}_{1}$ : Yapısal kırılmalar altında değişkenler arasında eş bütünleşme ilişkisi vardır.

Uzun dönemde değişkenler arasındaki eşbütünleşme ilişkisinden sonra uzun dönem katsayılarının tahminine olanak sağlayan FMOLS testinden yararlanılmaktadır. FMOLS katsayı tahmincisinde Maki eşbütünleşme testinde yer alan kırılma tarihleri regresyona dahil edilmektedir.

Değişkenler arasındaki ilişkinin yönü, Toda - Yamamoto (1995) nedensellik yaklaşımı ile test edilmektedir. Nedensellik testinde yer alan VAR modelinde, gecikme uzunluğu $(k)$ belirlenmektedir. $k$ gecikme uzunluğuna, değişkenin en yüksek bütünleşme derecesi olan dmax ilave edilmektedir. 


\subsection{Araştırmanın Bulguları ve Analizi}

Değişkenler arasında uzun dönemli bir ilişkinin varlığını test etmek için öncelikle birim kök testleri ile durağanlık sınaması yapılması gerekmektedir. Geleneksel birim kök testlerinden olan ADF ve PP birim kök testleri Tablo 3 ve yapısal kırılmaya izin veren Zivot - Andrews birim kök testi sonuçları Tablo 4'de gösterilmiştir.

Tablo 3: ADF ve PP Birim Kök Testi Sonuçları

\begin{tabular}{lllllllll}
\hline & Düzey & \multicolumn{3}{c}{ Birincil fark } & Düzey & \multicolumn{2}{l}{ Birincil fark } \\
\hline Seriler & Sabit & Trendli & Sabit & Trendli & Sabit & Trendli & Sabit & Trendli \\
\hline \multirow{2}{*}{ Gdp } & 0.17691 & -2.28186 & -6.24385 & -6.21263 & 0.438917 & -2.34746 & -6.38896 & -6.38649 \\
& $(0.9672)$ & $(0.4326)$ & $(0.0000)$ & $(0.0000)$ & $(0.9819)$ & $(0.6826)$ & $(0.0000)$ & $(0.0000)$ \\
\hline \multirow{2}{*}{ Tertiary } & 8.86815 & 3.72069 & -1.04040 & -3.57277 & 8.311338 & 3.41173 & -1.86059 & -3.79152 \\
& $(0.9957)$ & $(0.9828)$ & $(0.7274)$ & $(0.0470)$ & $(0.9994)$ & $(0.9999)$ & $(0.3463)$ & $(0.0290)$ \\
\hline \multirow{2}{*}{ Secondary } & -0.14204 & -2.67480 & -6.72299 & -6.67266 & -0.11943 & -2.74099 & -5.99463 & -5.89473 \\
& $(0.9383)$ & $(0.2514)$ & $(0.0000)$ & $(0.0000)$ & $(0.9410)$ & $(0.2259)$ & $(0.0000)$ & $(0.0000)$ \\
\hline \multirow{2}{*}{ Primary } & -0.28884 & -3.00229 & -6.36753 & -6.33317 & -2.62936 & -2.09772 & -6.36542 & -6.33317 \\
& $(0.9169)$ & $(0.7236)$ & $(0.0000)$ & $(0.0000)$ & $(0.0976)$ & $(0.2032)$ & $(0.0000)$ & $(0.0000)$ \\
\hline Physical & -1.67527 & -2.45751 & -5.51289 & -5.43603 & -1.67357 & -2.61475 & -5.73936 & -5.77176 \\
Capital & $(0.4349)$ & $(0.3459)$ & $(0.0000)$ & $(0.0000)$ & $(0.4357)$ & $(0.2764)$ & $(0.0000)$ & $(0.0000)$ \\
\hline \multicolumn{2}{l}{ Not: Parantez içindeki değerler olasilı değerlerini göstermektedir. } & & & & & &
\end{tabular}

Tablo 3'e göre, ADF ve PP test sonuçlarındaki bütün değişkenler I(0) düzeyinde birim köklü olduğundan Ho hipotezi kabul edilmiştir. Değişkenlerin birinci dereceden farkı alındığında, Ho hipotezi red edilerek alternatif hipotez kabul edilmiştir. ADF ve PP birim kök testlerinde yapısal kırılmaları göz ardı edildiği için Tablo 4'de yapısal kırılmaları dikkate alan Zivot - Andrews birim kök testine yer verilmiştir.

Tablo 4: Zivot - Andrews Birim Kök Testi Sonuçları

\begin{tabular}{|c|c|c|c|c|c|c|}
\hline & Model & Kurılma tarihi & $t$ istatistiği & $\% 1$ & $\% 5$ & $\% 10$ \\
\hline \multirow{2}{*}{ Gdp } & $\mathrm{A}$ & 1999 & -3.25700 & -5.34 & -4.93 & -4.58 \\
\hline & $\mathrm{C}$ & 1999 & -4.41647 & -5.57 & -5.08 & -4.82 \\
\hline \multirow{2}{*}{ d(gdp) } & $\mathrm{A}$ & 2003 & -6.73363 & -5.34 & -4.93 & -4.58 \\
\hline & $\mathrm{C}$ & 2003 & -6.61769 & -5.57 & -5.08 & -4.82 \\
\hline \multirow{2}{*}{ Tertiary } & $\mathrm{A}$ & 1991 & -0.70557 & -5.34 & -4.93 & -4.58 \\
\hline & $\mathrm{C}$ & 2007 & -4.31694 & -5.57 & -5.08 & -4.82 \\
\hline \multirow{2}{*}{ d(tertiary) } & $\mathrm{A}$ & 2009 & -8.01346 & -5.34 & -4.93 & -4.58 \\
\hline & $\mathrm{C}$ & 2009 & -7.76235 & -5.57 & -5.08 & -4.82 \\
\hline \multirow{2}{*}{ Secondary } & $\mathrm{A}$ & 1999 & -3.54459 & -5.34 & -4.93 & -4.58 \\
\hline & $\mathrm{C}$ & 1999 & -3.85359 & -5.57 & -5.08 & -4.82 \\
\hline \multirow{2}{*}{ d(secondary) } & $\mathrm{A}$ & 1999 & -6.67127 & -5.34 & -4.93 & -4.58 \\
\hline & $\mathrm{C}$ & 1999 & -6.71414 & -5.57 & -5.08 & -4.82 \\
\hline \multirow{2}{*}{ Primary } & A & 1993 & -3.47991 & -5.34 & -4.93 & -4.58 \\
\hline & $\mathrm{C}$ & 1993 & -3.53098 & -5.57 & -5.08 & -4.82 \\
\hline \multirow{2}{*}{ d(primary) } & A & 1999 & -6.71010 & -5.34 & -4.93 & -4.58 \\
\hline & $\mathrm{C}$ & 1999 & -6.97231 & -5.57 & -5.08 & -4.82 \\
\hline \multirow{2}{*}{ pyhsical capital } & $\mathrm{A}$ & 1998 & -4.08267 & -5.34 & -4.93 & -4.58 \\
\hline & $\mathrm{C}$ & 1999 & -4.12042 & -5.57 & -5.08 & -4.82 \\
\hline \multirow{2}{*}{ d(pyhsical capital) } & A & 1989 & -5.84332 & -5.34 & -4.93 & -4.58 \\
\hline & $\mathrm{C}$ & 1989 & -6.36759 & -5.57 & -5.08 & -4.82 \\
\hline
\end{tabular}

Not: Zivot - Andrews (1992) birim kök testlerinde Model A'ya göre, kritik değerleri -5.34, -4.93, -4.58; Model C'ye göre, -5.57, -5.08, -4.82 olarak belirlenmiştir.

Tablo 4'te, bütün değişkenlerin birinci dereceden farkı alındığında t- istatistik değerleri, kritik değerlerinden daha yüksek olduğundan durağandır. Kırılma tarihlerinin 1989, 1999, 2003 ve 2009 yılları olduğu görülmüştür. Bu yapısal kırılm tarihleri inceledindiğinde 1989 yılında Türk Parasının Kıymetini Koruma Hakkında çıkarılan 32. sayılı kararla TL konvertibl hale getirilmesi ve sermaye hareketlerinin serbestleştirilmesi, 1999'da Gölcük depremi ve Rusya krizinin yarattığı reel sektörde ve dış ticaret hacmindeki daralma, 2003 y1lında eğitim sisteminde değişiklikler, 2009'da küresel ekonomik kriz Türkiye'yi etkileyen olaylardır. Ayrıca, Avrupa Komisyonu'nun yaptığ 2008'deki krizinde en yüksek düzeylere çıkan işsizliğin 2009'da da devam ettiğini ve en yüksek işsizlik oranlarının ilk sırasında ortaöğretim mezunları, ikinci sırasında da yükseköğretim mezunlarının olduğu belirtilmiştir. 
Birim kök testlerinden sonra beş kırılmaya kadar izin veren Maki eş bütünleşme testi ile değişkenler arasında uzun dönemde bir ilişkinin olup olmadığı ortaya konulmuş (Maki, 2012), elde edilen veriler Tablo 5'de gösterilmiştir.

Tablo 5: Maki Eş Bütünleşme Testi Sonuçları

\begin{tabular}{cccc}
\hline Model & Test istatistikleri & Kritik değer & Kırılma tarihleri \\
\hline Model 0 & $-.8 .5631^{*}$ & -6.856 & $2002,2006,2009,2013,1995$ \\
\hline Model 1 & -5.0754 & -7.053 & $2012,1987,2011,1998,2015$ \\
\hline Model 2 & -7.3862 & -9.441 & $2007,1999,2003,1994,1984$ \\
\hline Model 3 & -7.6103 & -10.08 & $2003,1994,2013,2007,1997$ \\
\hline
\end{tabular}

Not: Kritik değerler için Maki (2012) çalışmasından yararlanılmıştır. * \%1 düzeyinde anlamlılı̆̆ı ifade etmektedir.

Tablo 5'de, Model 0'da \%1 önem düzeyinde değişkenler arasında uzun dönemde eş bütünleşme ilişkisinin olduğu görülmektedir. Ho hipotezi red edilerek alternatif hipotez kabul edilmektedir. Model 0 'da verilen beş kırılma tarihlerinden 2002 yılında Türkiye'de tek bir siyasi partinin iktidara gelmesi, 2009 yılında, eğitim sisteminde değişiklik ile üniversiteye giriş sınavlarında katsayı uygulaması kaldırılarak, üniversiteye giriş sınavları iki aşamalı hale getirilmesi ve küresel ekonomik krizin etkisi bu dönemlerde gerçekleşmiş̧ir. Eş bütünleşme testinden sonra değişkenler arasındaki ilişki Tablo 6' da FMOLS test sonuçlarında gösterilmiş, FMOLS tahmincisinde Maki eş bütünleşme testinde yer alan kırılma tarihleri de eklenmiştir.

Tablo 6: FMOLS Tahminci Sonuçları

\begin{tabular}{lcc}
\hline Değișkenler & Katsayı & t istatistiği \\
\hline Sabit & 0.010254 & $5.287412(0.000)$ \\
\hline Tertiary & 0.00975 & $2.066560(0.004)$ \\
\hline Secondary & -0.001678 & $-3.440569(0.002)$ \\
\hline Primary & 0.001028 & $1.377705(0.1805)$ \\
\hline Physical capital & 0.004727 & $8.316597(0.0000)$ \\
\hline Dummy 1 & 0.008670 & $1.181801(0.2484)$ \\
\hline Dummy 2 & 0.008116 & $1.105232(0.2796)$ \\
\hline Dummy 3 & 0.0023949 & $3.296618(0.029)$ \\
\hline Dummy 4 & -0.032323 & $-3.416328(0.0022)$ \\
\hline Dummy 5 & 0.020240 & $1.733728(0.0953)$ \\
\hline
\end{tabular}

Not: Parantez içerisindeki yer alan değerler olasılık değerlerini ifade etmektedir. *,**,*** sırasılla \%1, \%5 ve \%10 olasılık değerlerini göstermektedir.

Tablo 6'ya göre, yükseköğretim ve fiziki sermayenin ekonomik büyüme üzerindeki etkisi istatiksel olarak anlamlı ve pozitif yöndedir. Çalışmada elde edilen sonuçlar literatür taramasında yer alan Çoban (2004), Hanif ve Arshed (2016) çalışmalarındaki bulgular ile tutarlılık göstermektedir. Ortaöğretim kayıt oranlarının ekonomik büyüme üzerindeki etkisi istatiksel olarak anlamlı ve negatif yönde bulunmuştur. Kırılma tarihleri dummy 1 (2002), dummy 2 (2006), dummy 3 (1995), dummy 4 (2009) dummy 5 (2013) yılları ifade etmektedir. Buna göre, 1995'deki kırılmanın ekonomik büyüme üzerindeki etkisi istatiksel olarak anlamlı ve pozitiftir. 2009'da kırılmanın büyüme üzerindeki etkisi negatif yöndedir. Değişkenlerin kısa ve uzun dönem katsayıları tahmin edildikten sonra Tablo 7'de değişkenler arasındaki ilişkinin yönü Toda-Yamamoto nedensellik testi ile incelenmiştir. Schwarz bilgi kriterine göre, gecikme uzunluğu olan $\mathrm{k} 1$ olarak, dmax ise 4 olarak belirlenmiştir.

Tablo 7: Toda - Yamamoto Nedensellik Testi Sonuçları

\begin{tabular}{|c|c|c|c|c|c|}
\hline$\rightarrow$ & Gdp & Tertiary & Secondary & Primary & Physical Capital \\
\hline Gdp & - & $\begin{array}{c}8.577733 \\
(0.1271)\end{array}$ & $\begin{array}{c}5.776474 \\
(0.3286)\end{array}$ & $\begin{array}{l}53.21467 \\
(0.0000)^{*}\end{array}$ & $\begin{array}{c}1.249837 \\
(0.9400)\end{array}$ \\
\hline Tertiary & $\begin{array}{l}15.35934 \\
(0.0089)^{*}\end{array}$ & 2 & $\begin{array}{l}15.19280 \\
(0.0096)^{*}\end{array}$ & $\begin{array}{l}50.50717 \\
(0.0000)^{*}\end{array}$ & $\begin{array}{c}13.97262 \\
(0.0158)^{* *}\end{array}$ \\
\hline Secondary & $\begin{array}{l}19.76003 \\
(0.0014)^{*}\end{array}$ & $\begin{array}{l}30.46746 \\
(0.0000) \\
\end{array}$ & 20.008 & $\begin{array}{c}22.29152 \\
(0.0000) \\
\end{array}$ & $\begin{array}{c}15.93137 \\
(0.0170)^{* * *}\end{array}$ \\
\hline Primary & $\begin{array}{l}5.213478 \\
(0.3904) \\
\end{array}$ & $\begin{array}{l}7.703502 \\
(0.1734) \\
\end{array}$ & $\begin{array}{c}6.359486 \\
(0.2728) \\
\end{array}$ & - & $\begin{array}{c}11.39192 \\
(0.0441)^{* * *}\end{array}$ \\
\hline Physical capital & $\begin{array}{l}4.440441 \\
(0.4879) \\
\end{array}$ & $\begin{array}{c}2.196480 \\
(0.8213) \\
\end{array}$ & $\begin{array}{c}2.196480 \\
(0.8213) \\
\end{array}$ & $\begin{array}{l}38.64667 \\
(0.0000)^{*}\end{array}$ & 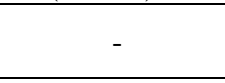 \\
\hline
\end{tabular}

Not: Parantez içerisindeki yer alan değerler olasılık değerlerini ifade etmektedir. $*, * *,{ }^{* * *}$ sırasıyla $\% 1, \% 5$ ve $\% 10$ olasılık değerlerini göstermektedir. 
Tablo 7'deki Toda-Yamamoto nedensellik testi sonuçlarına göre, ortaöğretim ve yükseköğretimde kayıt oranlarından ekonomik büyümeye doğru tek yönlü nedensellik ilişkisi bulunmaktadır. Ancak ekonomik büyümeden ortaöğretim ve yükseköğretim kayıt oranlarına doğru nedensellik ilişkisi bulunamamıştır. Yükseköğretimde sadece ortaöğretim kayıt oranında ve ilköğretim, ortaöğretim ve yükseköğretim kayıt oranlarından fiziki sermayeye tek yönlü nedensellik ilişkisi olduğu görülmüştür. Ancak nedensellik testinde, sadece fiziki sermayeden ve ekonomik büyümeden ilköğretim kayıt oranına bir ilişki olduğu tespit edilmiştir. Testin sonucunda ortaöğretim kayıt oranlarından ve yükseköğretim kayıt oranlarından bütün değişkenlere doğru nedensellik ilişkisinin olduğu ortaya konulmuştur.

\section{SONUÇ}

Küreselleşen dünyada, az gelişmiş ve gelişmekte olan ülkeler arasındaki farklılıklar daha da belirgin hale gelmiştir. $\mathrm{Bu}$ farklılıkları oluşturan en temel faktörlerden biri, eğitim yoluyla üretim sürecine katılan işgücünün bilgi ve becerisini arttırarak daha verimli ve etkin kullanmasını sağlayan beşeri sermayedir. Bu temel faktör zamanla, Cobb - Douglas üretim fonksiyonunda fiziksel sermaye ve emek faktörüne ek girdi olarak yerini almıştır. Dünya Ekonomik Forumu'nun on iki adımda belirlediği rekabet gücü adımlarından birini beşeri sermaye unsurlarından olan eğitim ve sağlık oluşturmaktadır.

Bu çalıșmada ilköğretim, orta öğretim ve yükseköğretim kayıt oranlarının ve fiziki sabit sermayenin ekonomik büyüme üzerindeki etkisi incelenmektedir. Cobb-Douglas üretim fonksiyonunda yararlanıldığı modelde işgücü yerine okul kayıt oranları, sermaye yerine de fiziki sabit sermaye değişkeni kullanılmıştır. 1980-2016 döneminin incelendiği çalışmada değişkenlere ait veriler World Bank veri tabanından elde edilmiştir. Analizin ilk aşamasında, geleneksel birim kök testlerinden ADF ve PP birim kök testleri yapılmıştır. Yapısal kırılmaların dikkate alınmadığı ADF ve PP birim kök testlerinden sonra, yapısal kırılmaya izin veren Zivot-Andrews birim kök testi uygulanmıştır. Birinci derecede farkında durağan olan değişkenler arasındaki uzun dönemli ilişkinin varlığ Maki eş bütünleşme testi ile incelenmiştir. Beş yapısal kırılmaya kadar izin veren Maki eş bütünleşme testinde uzun dönemde değiş̧kenler arasında ilişkinin olduğu tespit edilmiştir. Uzun dönem katsayı tahminleri için FMOLS eş bütünleşme katsayı tahmincisi uygulanmış, yükseköğretim ve fiziki sermayenin ekonomik büyüme üzerinde etkisi istatiksel olarak anlamlı ve pozitif bulunmuştur. Değişkenler arasındaki ilişkinin yönünü inceleyen Toda-Yamamoto nedensellik testi sonuçlarına göre, ortaöğretim ve yükseköğretim kayıt oranlarından ekonomik büyümeye doğru tek yönlü; ilköğretim, orta öğretim ve yükseköğretim kayıt oranlarından fiziki sermayeye tek yönlü nedensellik ilişkisi bulunmuştur. Ancak nedensellik testinde, sadece fiziki sermayeden ve ekonomik büyümeden ilköğretim kayıt oranına doğru bir nedensellik ilişkisi olduğu görülmüştür.

Çalışmada yükseköğretimde okullaşma ile ekonomik büyüme arasındaki ilişkide elde edilen sonuçlar daha önce yapılan çalışmalarla tutarlılık göstermektedir. Okullaşma oranlarının artışı iyi bir gösterge olurken Türkiye'yi OECD ülkeleri ile karşılaş̧ırdığımızda hem beşeri sermaye bakımından hem de kişi başına milli gelir bakımından geride kaldığını söyleyebiliriz. Bireysel ve toplumsal refah düzeyinin yükselmesi için eğitime yapılan harcamaların arttırılması ve eğitimde niteliksel gelişmeleri sağlayacak adımların atılması gerekmektedir. Eğitim yolu ile bireye yapılan yatırımlar, verimlilik artışı sağlayarak kişi başına gelir artırır ve dolayısıyla ekonomik büyüme sağlanır.

Etik Beyan: Bu çalışmada "Etik Kurul” izini alınmasını gerektiren bir yöntem kullanılmamıştır.

Yazar Katkı Beyant:1. Yazarın katkı oranı \%60 2. Yazarın katkı oranı ise \%40’tır.

Çıkar Beyanı: Yazarlar arasında çıkar çatışması yoktur.

Ethics Statement: In this study, no method requiring the permission of the "Ethics Committee" was used.

Author Contributions Statement: 1st author's contribution rate 60\%, 2nd author's contribution rate $40 \%$.

Conflict of Interest: There is no conflict of interest among the authors. 


\section{KAYNAKÇA}

Abbas, Q., \& Foreman-Peck, J. (2007). Human capital and economic growth: Pakistan, 1960-2003. Cardiff Economics Working Paper Series, (No. E2007/22), 1-21, http://orca.cf.ac.uk/40496/2/Human\%20K\%20\%26\%20Econ\%20Growth\%2016th\%20june\%20 2008.pdf

Acemoglu, D., \& Angrist, J. (2000). How large are human-capital externalities? Evidence from compulsory schooling laws. NBER Macroeconomics Annual, 15, 9-59. https://www.journals.uchicago.edu/doi/pdf/10.1086/654403

Afşar, M. (2009). Türkiye'de eğitim yatırımları ve ekonomik büyüme ilişkisi. Anadolu Üniversitesi Sosyal Bilimler Dergisi, $\quad 9(1), \quad 85-98$. https://earsiv.anadolu.edu.tr/xmlui/bitstream/handle/11421/19141/19141.pdf?sequence=1\&isAll owed=y

Afzal, M., Farooq, M. S., Akmad, H. K., Begum, I., \& Quddus, M. A. (2010). Relationship between school education and economic growth in Pakistan: ARDL bounds testing approach to cointegration. Pakistan Economic and Social Review, 48(1), 39-60. http://pu.edu.pk/images/journal/pesr/PDF-FILES/3\%20AFZAL\%20Relationship\%20e\% 20School\%20Education\%20and\%20Economic\%20Growt\%2085.pdf

Akçacı, T. (2013). Eğitim harcamalarının iktisadi büyümeye etkisi. Kafkas Üniversitesi İktisadi ve İdari Bilimler Fakültesi Dergisi, $\quad 4$ 65), https://www.acarindex.com/dosyalar/makale/acarindex-1423906482.pdf

Akkoyunlu-Wigley, A., \& Wigley, S. (2008). Basic education and capability development in Turkey. Education in Turkey, 2008, 271-297. https://papers.ssrn.com/sol3/papers.cfm?abstract_id=1292227

Aktan, O., \& Akkutay, Ü. (2014). OECD ülkelerinde ve Türkiye'de okulöncesi eğitim. Asya Öğretim Dergisi, 2(1), 64-79, https://dergipark.org.tr/en/download/article-file/17642.

Ali, M., Egbetokun, A. A., \& Memon, M. H. (2016). Human capital, social capabilities and economic growth (No. 2016-013). Jena Economic Research Papers, 1-25. https://www.econstor.eu/bitstream/10419/148892/1/872837211.pdf

Barro, R. J. (1991). Economic growth in a crosssection of countries. The Quarterly Journal of Economics, 106(2), 407-443. https://doi.org/10.2307/2937943

Barro, R. J. (2001). Human capital and growth. American Economic Review, 91(2), 12-17. https://www.aeaweb.org/articles/pdf/doi/10.1257/aer.91.2.12

Becker, G. (1975). Human capital: A theoretical and empirical analysis, with special reference to education. (2. Edition). NBER Books.

Benos, N., \& Zotou, S. (2014). Education and economic growth: A meta-regression analysis. World Development, 64, 669-689. https://doi.org/10.1016/j.worlddev.2014.06.034

Bils, M., \& Klenow, P.J. (2000). Does schooling cause growth?. American Economic Review, 90(5), 1160-1183. https://doi.org/10.1257/aer.90.5.1160

Blundell, R., Dearden, L., Meghir, C., \& Sianesi, B. (2005). Human capital investment: There turns from education and training to the in dividual, the firm and the economy. Fiscal Studies, 20(1), 1-23. https://doi.org/10.1111/j.1475-5890.1999.tb00001.x

Brown, P. H., \& Park, A. (2002). Education and poverty in rural China. Economics of Education Review, 21(6), 523-541. https://doi.org/10.1016/S0272-7757(01)00040-1

Canpolat, N. (2000). Türkiye'de beşeri sermaye birikimi ve ekonomik büyüme. Hacettepe Üniversitesi İktisadi ve İdari Bilimler Fakültesi Dergisi, 18(2), 265-281. https://dergipark.org.tr/en/download/article-file/323051 
Chatterji, M. (1998). Tertiary education and economic growth. Regional Studies, 32(4), 349-354. https://doi.org/10.1080/00343409850117807

Costantini, V., \& Monni, S. (2008). Environment, human development and economic growth. Ecological Economics, 64(4), 867-880. https://doi.org/10.1016/j.ecolecon.2007.05.011

Çalışkan, Ş. (2007). Eğitim-işsizlik ve yoksulluk ilişkisi. Selçuk Üniversitesi İ̈BF Sosyal ve Ekonomik Araştırmalar Dergisi, 7(13), 284-308. https://dergipark.org.tr/en/download/article-file/289512

Çoban, O. (2004). Beşeri sermayenin iktisadi büyüme üzerine etkisi: Türkiye örneği. İstanbul Üniversitesi Siyasal Bilgiler Fakültesi Dergisi, (30), 131-142. https://dergipark.org.tr/en/download/article-file/5374

Dickey, D. A., \& Fuller, W. A. (1979). Distribution of the estimators for autoregressive time series with a unit root. Journal of the American Statistical Society, 75, 427-431. https://doi.org/10.1080/01621459.1979.10482531

European Comission (2016). Organization of the education system in Turkey 2009.2010. https://www.etf.europa.eu/sites

Földvári, P., \& Van Leeuwen, B. (2009). An alternative interpretation of 'average years of education'in growth regressions. Applied Economics Letters, 16(9), 945-949. https://doi.org/10.1080/13504850701222178

Gövdeli, T. (2016). Türkiye'de eğitim- ekonomik büyüme ilişkisi: Yapısal kırılmalı birim kök ve eş bütünleşme analizi. Niğde Üniversitesi İktisadi ve İdari Bilimler Fakültesi Dergisi, 9(3), 224238. https://dergipark.org.tr/en/download/article-file/226564

Gümüş, S., \& Kayhan, S. (2012). The relationship between economic growth hand school enrollment rates: Time series evidence from Turkey. Educational Policy Analysis and Strategic Research, 7(1), 24-38. https://files.eric.ed.gov/fulltext/EJ1127574.pdf

Gür, B. S., \& Çelik, Z. (2009). Türkiye'de milli eğitim sistemi yapısal sorunlar ve öneriler. SETA Raporu, Ekim, No.1.

Hanif, N., \& Arshed, N. (2016). Relation between school education and economic growth: SAARC countries. International Journal of Economics and Financial Issues, 6(1), 294-300. https://www.econjournals.com/index.php/ijefi/article/view/1605/pdf

Hanushek, A. E., \& Kimko, D. (2000). Schooling, labor-force quality, and the growth of nations. The American Economic Review, 90(5), 1184-1208. https://www.aeaweb.org/articles?id=10.1257/aer.90.5.1184

Keller, K. (2006). Investment in primary, secondary and higher education and the effects on economic growth. Contemporary Economic Policy, 24(1), 18-34. https://doi.org/10.1093/cep/byj012

Kotásková, S. K., Procházka, P., Smutka, L., Maitah, M. Kuzmenko, E., Kopecká, M., \& Hönig, V. (2018). The impact of education on economic growth: The case of India. Acta Universitatis Agriculturae Et Silviculturae Mendelianae Brunensis, 66(1), 253-261. https://acta.mendelu.cz/media/pdf/actaun_2018066010253.pdf

Lawal, N. A. (2011). Education and economic growth: The Nigerian experience. Journal of Emerging Trends in Economics and Management Sciences, 2(3), 225-231. https://journals.co.za/doi/abs/10.10520/EJC134170

Lucas, R. E. (1988). On the mechanics of economic development. Journal of Monetary Economics, 22(1), 3-42. https://doi.org/10.1016/0304-3932(88)90168-7

Maki, D. (2012). Tests for cointegration allowing for an unknown number of breaks. Economic Modeling, 29(5), 2011-2015. https://doi.org/10.1016/j.econmod.2012.04.022

MEB (2018). Eğitim istatistikleri. https://www.meb.gov.tr 
Mincer, J. (1974). Schooling, experience, and earnings. Human Behavior \& Social Institutions No. 2. NBER Books.

Miyazawa, K. (2017). Measuring in human capital in japan, policy research institute, ministry of finance, Japan. Public Policy Review, 13(3), 241-268. https://www.mof.go.jp/english/pri/publication/pp_review/fy2017/ppr13_03_02.pdf

Njong, A. M. (2010). The effects of educational attainment on poverty reduction in Cameroon. International Journal of Educational Administration and Policy Studies, 2(1), 001-008. https://academicjournals.org/journal/IJEAPS/article-full-text-pdf/187739F814

OECD (2019). The value of people, https://www.oecd.org/insights/37967294.pdf

Oxaal, Z. (1997). Education and poverty: A gender analysis report (Report No. 53). Brighton: Institute of Development Studies, University of Sussex.

ÖSYM (2019). Yükseköğretim istatistikleri, https://www.osym.gov.tr

Özsoy, C. (2010). Türkiye'de eğitim ve iktisadi büyüme arasındaki ilişkinin VAR modeli ile analizi. Bilgi Ekonomisi ve Yönetimi, 5(1), 71-83. http://beykon.org/dergi/2009/BAHAR/C.Ozsoy.pdf

Pamuk, M., \& Bektaş, H. (2014). Türkiye'deki eğitim harcamaları ile ekonomik büyüme arasındaki ilişki. Siyaset, Ekonomi ve Araştırmalar Dergisi, 2(2), 77-89, https://dergipark.org.tr/en/pub/seyad/issue/53403/710216

Psacharopoulos, G., \& Patrinos, H. A. (2004). Returns to investment in education: A further update. Education Economics, 12(2), 111-134 https://doi.org/10.1080/0964529042000239140

Reza, F., \& Widodo, T. (2013). The impact of education on economic growth in Indonesia. Journal of Indonesian Economy \& Business, 28(1), https://core.ac.uk/download/pdf/297708394.pdf

Seetanah, B. (2009). The economic importance of education: Evidence from Africa using dynamic panel data analysis. Journal of Applied Economics, 12(1), 137-157, https://doi.org/10.1016/S1514-0326(09)60009-X

Taban, S., \& Kar, M. (2014). Kalkınma ekonomisi. Ekin Basım Yayın Dağıtım.

Telatar, O. M., \& Terzi, H. (2010). Nüfus ve eğitimin ekonomik büyümeye etkisi: Türkiye üzerine bir inceleme. Atatürk Üniversitesi İktisadi ve İdari Bilimler Dergisi, 24(2), 197-214, https://dergipark.org.tr/en/download/article-file/30303

Teixeira, A. A., \& Queirós, A. S. (2016). Economic growth, human capital and structural change: A dynamic panel data analysis. Research Policy, 45(8), 1636-1648, https://doi.org/10.1016/j.respol.2016.04.006.

The World Bank (2019). Education statistic, www. worldbank.org.uis.unesco.org/country/TR

Wedgwood, R. (2007). Education and poverty reduction in Tanzania. International Journal of Educational Development, 27(4), 383-396, https://doi.org/10.1016/j.ijedudev.2006.10.005

Yeşilyurt, M. E., Karadeniz, O., Gülel, F. E., Çağlar, A., \& Uyar, S. G. (2016). Türkiye'de illere göre ortalama ve beklenen okullaşma y1l. Pamukkale Journal of Eurasian Socioeconomic Studies, 3(1), 1-7, https://dergipark.org.tr/en/download/article-file/398713

YÖK (2018). Yükseköğretim istatistikleri. https://www.yok.gov.tr

Zivot, E., \& Andrews, D. W. K. (2002). Further evidence on the great crash, the oil-price shock, and the unit-root hypothesis. Journal of Business \& Economic Statistics, 20(1), 25-44, https://doi.org/10.1198/073500102753410372 